Gynaecologia 1963;156:1

\title{
Gynakologische Gesellschaft der Deutschen Schweiz
}

Herbstversammlung am 24./25. November 1962 in Bern

Verzeichnis de $\Gamma$ Vorträge

Arnold, M. und Ríchter, R. if. if.: Hormonausscheidung bei

normalen und hirsuten Frauen nach Testosteronbelastung 2

Büchele, F. und Herrmann, U.: Beit $\Gamma$ ag zur spasmolytischen

Wirkung von Vabum ${ }^{\circledR}$ unter der Geburt

7

Stamm, if.; Caflisch, A. und Mall, M.: Diagnose und Therapie

der Afibrinogenämie post partum

12

Haefelí, if.: Untersuchungen über vagale, die Herztätigkeit

beeinflussende Reflexe bei neugeborenen Exenzephalen ... 18

Mall, M. und Stamm, if.; Fruchtwasserembolie und Afibrinogenämie post partum

Müller, J. if.: Zur Anwendung des kolloidalen Radiogoldes fürdie präoperative interstitielle paraselektive Vorbestrahlungdes Brustkrebses. Vorläufige Ergebnisse und dosimetrischeDaten (Neutronenaktivierungsanalyse) 36

Ríchter, R. H. if.: Über die Wirkung einiger Steroide auf die embryonale und fötale Entwicklung der Ratte

W. Wenner, JR.: Transvesikale Operation von Vesico-Vaginalfisteln 47

1 Gynaecologia, Vol. 156, No. 1 (1963) 